\title{
Pathobiology
}

de Leng, W.W.J. 339

Hoefler, G. 289

Ilyas, M. 292

Jonges, T. 339

Kashofer, K. 323

Langenberg, M.H.G. 339

Liegl-Atzwanger, B. 323
Stenzinger, A. 306

Szurian, K. 323

van Winkel, E. 339

Weichert, W. 306

Willems, S.M. 339

Witteveen, P.O. 339

\section{Subject Index Vol. 84, No. 6, 2017}

Biomarker 306, 339

Bone tumors 323

Cancer 306

Cervical tumours 339

Diagnostic pathology 292

Digestive system 306

Drug target 306

Endometrial tumours 339

Genetic profiling 306

Gynaecological tumours 339
Molecular analysis 323

Mutation 339

Next-generation sequencing 292, 306, 323,339

Ovarian tumours 339

Predictive value 339

Prognostic value 339

Sarcomas 323

Soft-tissue tumors 323 